\title{
Development and Characterization of Biocolour (Beta vulgaris) Enriched Low Calorie Lassi (Yogurt Based Beverage)
}

\author{
Shairee Ganguly, Chaitali Chakraborty* and Kakali Bandyopadhyay \\ Department of Food Technology, Guru Nanak Institute of Technology, 157/F, Nilgunj Road, \\ Panihati, Kolkata-700114, West Bengal, India \\ *Corresponding author
}

\section{A B S T R A C T}

\section{Keywords}

Lassi, Betalain, Polyphenol, Freezedrying, 9 point hedonic scale, Proximate analysis.

Article Info

Accepted:

20 March 2017

Available Online:

10 April 2017
Lassi is a popular traditional yogurt based drink from the Indian Subcontinent. Lassi is a blend of yogurt, water, spices and sometimes fruits. To increase the physical acceptability of lassi, it has been fortified with betalain powder which provides reddish colour. Colour is an important parameter for sensory analysis and consumer preference. However using synthetic colour could be harmful for health. In today's progressive world a shift from synthetic to biocolour is observed. Betalain is a biocolour extracted from beet-root (Beta vulgaris). It also increases the polyphenol content of the product which will increase the anti-oxidant property of this beverage. In the present study, effort has been given to reduce the calories of lassi by using zero calorie sweetener, sucralose as it is 600 times sweeter than sucrose. To avoid the heat damage of biocolour, freeze dried powder is used as colorant. The polyphenol content of betalain powder is measured in gallic acid equivalents (GAE) by Folin-Ciocalteau assay using different solvents like methanol, ethanol, petroleum ether and water. Polyphenol content is increased from $755.32 \mathrm{gm} / 100 \mathrm{gm}$ for control lassi to $862.1 \mathrm{gm} / 100 \mathrm{gm}$ sample for fortified lassi. Proximate analysis of the lassi samples and the stability of betalain are also determined. Finally, the sensory evolution is also executed by using 9 point hedonic scale. Thus fortified lassi is prepared with enhanced functional properties as well as its overall acceptability.

\section{Introduction}

India is diversified country, famous for its tradition, culture in each field because of agro-climatic zone, language, etc. India is popular for its traditional beverages and foods. These traditional foods are significantly known for their taste and texture, nutritional and therapeutic value. The combination of this traditional knowledge with scientific knowledge will increase the demand of some fermented foods to the health conscious consumers. For example, lassi is a popular traditional yogurt based drink from the Indian Subcontinent. Lassi is a blend of yogurt, water, spices and sometimes fruits. In this present study, to increase the physical acceptability of lassi, it has been fortified with betalain (beet root color).

Again, effort has been given to reduce the calories of lassi by using non-nutritive sweetener, sucralose as it is 600 times sweeter than sucrose and has no calorie. 


\section{Betalain}

Colour is an important parameter for sensory analysis and consumer preference. However using synthetic colour could be harmful for health. In today's progressive world a shift from synthetic to biocolour is observed. Natural colourants have received increased acceptability, mainly because of their apparently less toxicity than artificial colourants. Natural colours are found to be nutritional antioxidants and their presence in diet can reduce the risk of cardiovascular diseases, cancer and diseases associated with ageing. The major pigments present abundantly in beetroot (Beta vulagaris L.) are betalains, which impart a desirable red colour to food and have numerous applications in food industry as additives in gelatins, desserts, confectioneries, baked foods, etc., (Aparnathi et al., 1999). Betalains have received an increased attention due to their antiviral and antimicrobial activities. The stability of betalains is strongly influenced by sugar, light, oxygen, water activity, $\mathrm{pH}$ and temperature (Delgado-Vargas et al., 2000).

Beet is a vegetable root of the family Chenopodiaceae. Its edible part is its tuberous root. The purple-red colour of beet-root is due to the presence of betalain pigments. Betalains are water-soluble nitrogenous pigments and are divided into two classes: red-violet betacyanin and yellow betaxanthin. Polyphenols and betalain pigments respond property's antioxidants benefic for the human health. (Kujala et al., 2002 and Vitti et al., 2005)

\section{Sucralose}

As here the effort is to make low calorie lassi, sugar substitute zero calorie sweetener sucralose is used. Sucralose is safe for consumption by diabetics and non-diabetics and does not affect insulin levels. It is a water soluble tri-chlorinated disaccharide that is 600 times sweeter than sugar. It is highly stable and will not readily degrade at high temperatures. Sucralose has a low human toxicity and is not metabolized by the human body. Results from over a hundred animal and clinical studies in the FDA approval process unanimously indicated a lack of risk associated with sucralose consumption.

\section{Materials and Methods}

\section{Preparation of crude betalain powder}

Beetroots were bought from local market (Sodepur, Kolkata). They were peeled, washed and grated. Distilled water was added with the grated beetroot in 2:1 ratio. The mixture is then centrifuged by using cold centrifugation (Remi C 24) 12000 r.p.m. for 10 minutes at $-5^{\circ} \mathrm{C}$. The extracted biocolour is dried by using freeze drier (Eyela FDU1200 freeze dryer) (Chakraborty et al., 2017).

\section{Determination of polyphenol content of freeze dried betalain by using different solvents}

Four solvents were used for polyphenol content extraction, like, petroleum ether, ethanol, methanol and water. The polyphenol content was determined by using UV-Vis $\begin{array}{llll}\text { spectrophotometer (Jasco } & \mathrm{V} & 630\end{array}$ Spectrophotometer) by standard Mcdonald et al., (2001) method and expressed in terms of gallic acid equivalent (GAE).

\section{Preparation of betalain fortified low calorie} lassi (Y2) and control lassi (Y1)

Fresh yogurt was bought from local market (Sodepur, Kolkata). 500gm yogurt was taken and $500 \mathrm{ml}$ chilled water was added. Then 1.6 ml. of sucralose (Sugarfree Natura Sweet Drops) was mixed. Then $2 \mathrm{gms}$ of the freeze dried crude betalain powder was added. In the other hand, control lassi (Y1) was prepared from same quantity of yogurt and chilled water. Here table sugar (sucrose) was added as sweetening agent. 


\section{Chemical analysis of Lassi}

The compositions and chemical parameters of Lassi samples were analyzed by the following standard procedures.

The total solids content of samples was determined by standard gravimetric method given in IS: SP: 18, (part Xl), 1981. Fat contents were determined by Gerber method as per procedure stated in IS: 1224 (Part-I), 1977. Nitrogen contents were estimated by micro-Kjeldahl method and converted to protein by using the factor 6.38 (AOAC, 1992).Lactose was determined as per LaneEynon's method given in IS: 1479 (Part-II) 1961.Acidity of Lassi samples were determined as per procedure stated in IS: 1479 (Part I) 1960. pH of Lassi determined by using digital $\mathrm{pH}$ meter $\left(\mathrm{pH}\right.$ meter $\mathrm{CL} 46^{+}$, Toshcon Industries Pvt., Ltd.) following the procedure stated in IS: 1479 (Part-II) 1961.

Ash contents were estimated as per procedure given in IS: 1479 (Part II), 1961.The polyphenol contents were determined by spectrophotometer by standard Mcdonald $e t$ al., (2001) method and expressed in terms of gallic acid equivalent (GAE) with water as solvent.

\section{Determination of the stability of Betalain}

Stability of betalain colour in different $\mathrm{pH}$ was determined by mixing different volume of $1(\mathrm{~N}) \mathrm{HCl}$ and $1(\mathrm{~N}) \mathrm{NaOH}$ to the crude betalain powder. $\mathrm{pH}$ was determined by using digital $\mathrm{pH}$ meter $\left(\mathrm{pH}\right.$ meter $\mathrm{CL} 46^{+}$, Toshcon Industries Pvt., Ltd.). As, the crude betalain demonstrated the maximum peak at $500 \mathrm{~nm}$ (Figure 1) (Chakraborty et al., 2017), the absorbance of the betalain in different $\mathrm{pH}$ solution (by addition of acid and alkali) were determined by using UV-Vis spectrophotometer (Jasco $\quad \mathrm{V} \quad 630$ Spectrophotometer) at $500 \mathrm{~nm}$ wavelength.

\section{Sensory analysis}

Sensory analysis was done for both betalain fortified low calorie lassi and control lassi by eight trained panel members of food technology department by using 9 point hedonic scale (Hooda and Jood, 2005).

\section{Results and Discussion}

\section{Polyphenol content of freeze dried betalain by using different solvents}

The polyphenol contents in different solvents are present in table 1. Maximum amount of polyphenol is extracted by water (9.59 $\mathrm{gm} / 100 \mathrm{gm})$.

\section{Stability of betalain at different $\mathrm{pH}$}

Stability of betalain in different $\mathrm{pH}$ is shown in figure 2.The maximum stability of betalain was found at $\mathrm{pH} 4.5$.

\section{Chemical analysis}

The results of proximate analysis of lassi samples are shown in table 2. The average values of fat, protein, lactose, ash content, total solid, acidity (\% LA), $\mathrm{pH}$ and polyphenol contents of control lassi was found as $3.15 \%, 3.52 \%, 3.57 \%, 1.1 \%, 26 \%$, $1.02 \%, \quad 4.92$ and $755.32 \mathrm{gm} \quad \mathrm{GAE} / \mathrm{ml}$ respectively. While these values for betalain fortified low calorie lassi was found as $3.1 \%$, $3.48 \%, 3.51 \%, 1.12 \%, 25.4 \%, 1.04 \%, 4.9$ and $862.1 \mathrm{gm} \mathrm{GAE} / \mathrm{ml}$ respectively.

\section{Sensory analysis}

Sensory analysis of lassi samples is shown in table 3. It is found that in case of the betalain fortified low calorie lassi, the colour and flavor are about $6 \%$, body texture and mouth feelness are about $4.5 \%$ and overall acceptance is about $4 \%$ more than the control lassi. 
Table.1 Polyphenol content (gm GAE/100gm) of freeze dried beetroot colour in different solvents

\begin{tabular}{|l|c|c|c|c|}
\hline Type of Solvents & Pet Ether & Ethanol & Methanol & Water \\
\hline gm GAE/100gm & $0.771 \pm 0.01$ & $0.2433 \pm 0.0137$ & $5.38 \pm 0.03$ & $9.59 \pm 0.09$ \\
\hline
\end{tabular}

$($ Avg \pm s.d. $)=$ Average \pm standard deviation, $\mathrm{n}=3$

Table.2 Proximate analysis of betalain fortified low calorie lassi

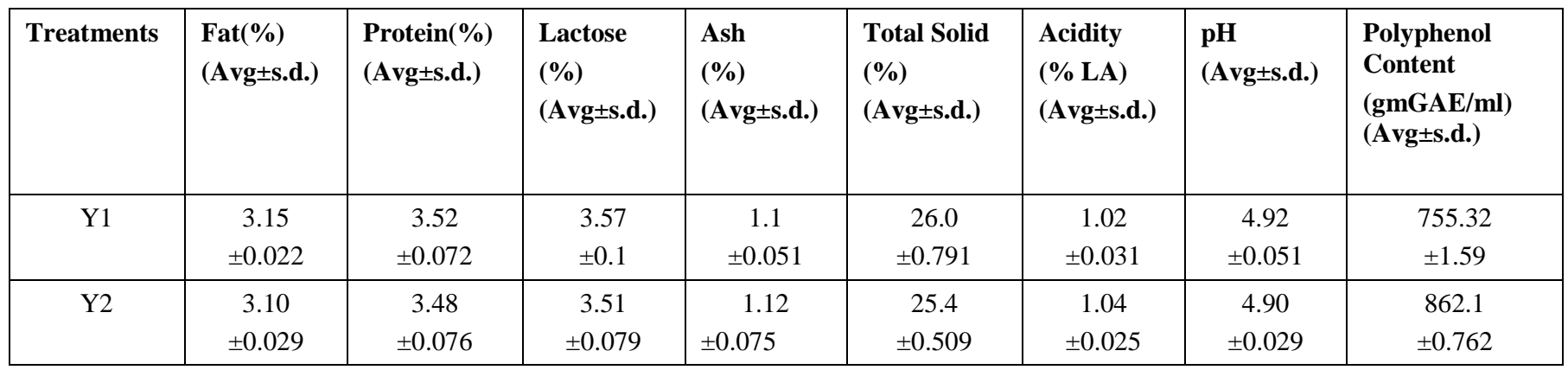

$($ Avg \pm s.d. $)=$ Average \pm standard deviation, $\mathrm{n}=5$

Figure.1 Peak line determination curve of betalain

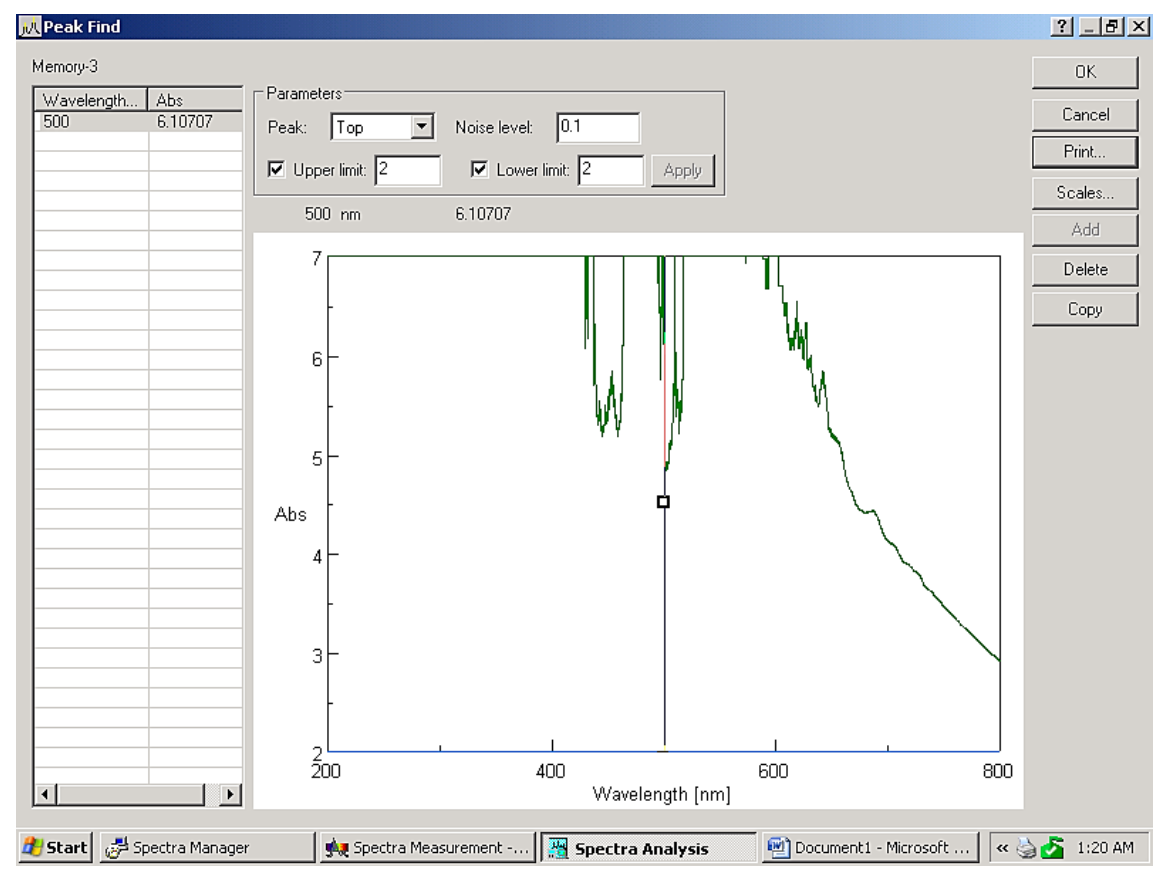


Table.3 Sensory analysis of betalain fortified low calorie lassi

\begin{tabular}{|l|l|l|l|l|l|l|}
\hline Sample & Appearance & Colour & Flavour & $\begin{array}{l}\text { Body and } \\
\text { Texture }\end{array}$ & Mouthfeelness & $\begin{array}{l}\text { Overall } \\
\text { Acceptance }\end{array}$ \\
\hline Y1 & $8.375 \pm 0.518$ & $8.25 \pm 0.463$ & $8.125 \pm 0.835$ & $8.375 \pm 0.744$ & $8.25 \pm 0.463$ & $8.3125 \pm 0.458$ \\
C.V. & 24.859 & 23.688 & 32.048 & 29.806 & 23.688 & 23.474 \\
S. Error & 0.18288 & 0.163572 & 0.294884 & 0.262906 & 0.163572 & 0.16186 \\
& & & & & & \\
\hline Y2 & $8.375 \pm 0.518$ & $8.75 \pm 0.463$ & $8.625 \pm 0.518$ & $8.75 \pm 0.463$ & $8.625 \pm 0.518$ & $8.65 \pm 0.407$ \\
C.V. & 24.495 & 22.361 & 24.495 & 22.361 & 24.495 & 22.361 \\
S.Error & 0.18288 & 0.163572 & 0.18288 & 0.163572 & 0.18288 & 0.143845 \\
\hline
\end{tabular}

$($ Avg \pm s.d. $)=$ Average \pm standard deviation, $\mathrm{n}=8$

Figure.2 Stability of betalain at different $\mathrm{pH}$

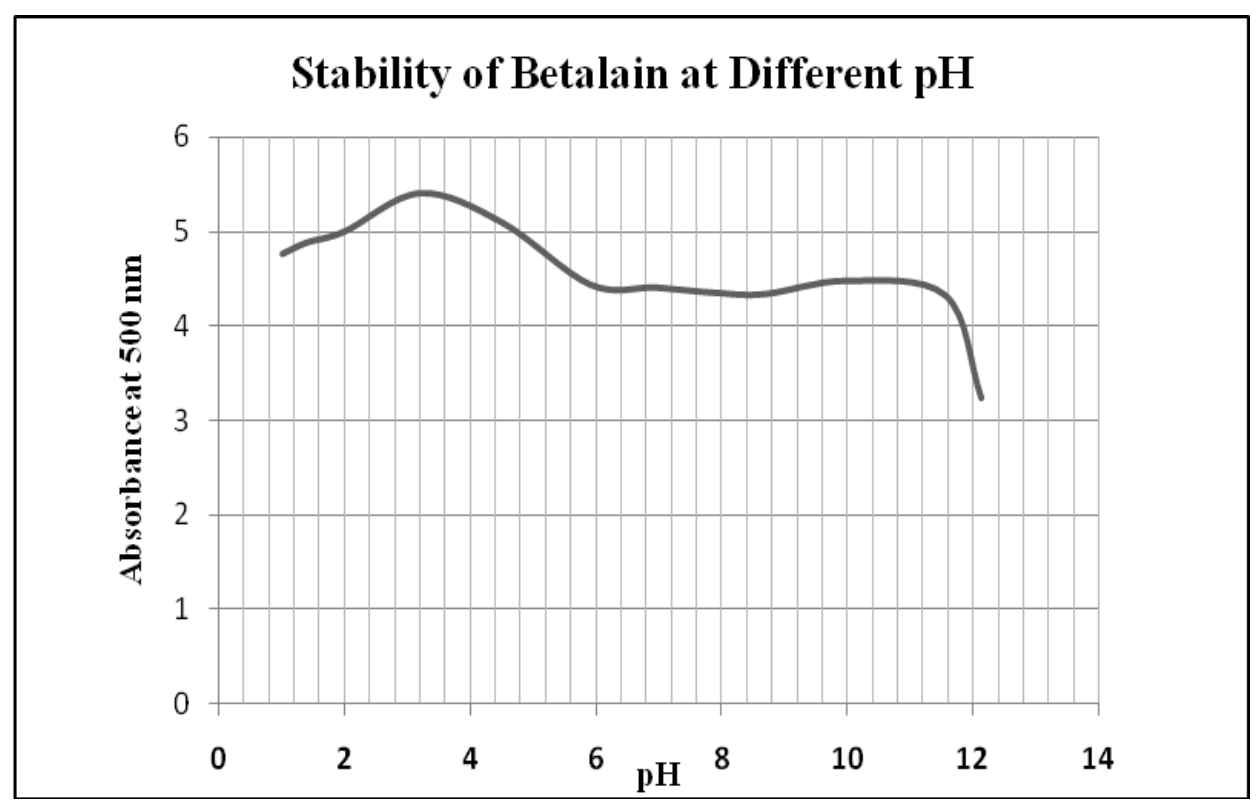

\section{Acknowledgement}

The authors are hereby acknowledging the Honorable Managing Director of JIS Group for financial support and inspiration.

\section{References}

AOAC. 1992. Official methods of analysis. 12th ed. Association of Official Analytical Chemists, Washington, DC.
Aparnathi, K.D., and Borkhatriya, V.N. 1999.Improved extraction and stabilization of natural food colorants. Indian Food Industry, 18(3): 164-168.

Chakraborty, C., K. Bandyopadhyay and Gangyly, S. 2016. Studies on Extraction and Characterization of Biocolour from Beet Root (Beta vulgaris), Adv. Life Sci., 5(21): 10150-10152.

Delgado-Vargas, F., Jimenez, A.R., \& Lopez, O.P. 2000. Natural pigments: 
Cartenoids, anthocyanins and betalains -characteristics, biosynthesis processing and stability. Critical Rev Food Sci. Nutri., 40(3): 173-289.

Hooda, S. and Jood, S. 2005. Organoleptic and nutritional evaluation of wheat biscuits supplemented with untreated and treated fenugreek flour. Food Chem., 90: 427-435.

ISI: 1479 (Part-I) 1960. Method of test of dairy industry, Rapid examination of milk. Indian Standard Institution. Manak Bhavan, New Delhi, India.

ISI: 1479 (Part-II) 1961. Method of test of dairy industry. Rapid examination of milk. Indian Standard Institution. Manak Bhavan, New Delhi, India.

IS: 1224 (Part I) 1977. Determination of fat by Gerber method. First Revision, Indian Standard Institute, Manak Bhavan, New Delhi, India.

IS: SP: 18 Part XI. 1981. ISI Handbook of food analysis-Dairy products. Bureau of Indian Standards, ManakBhavan, New Delhi, India.

Kujala, T.S., Vienola, M.S., Klika, K.D.,
Loponen, J.M. and Pihalja, K. 2002. Betalain and phenolic composition of four beetroot (Beta vulgaris) cultivars. European Food Res. Technol., 214: 505-510.

McDonald S., Prenzler P.D., Autolovich M. and Robards K. 2001. Phenolic content and antioxidant activity of olive extracts. Food Chem., 73:73-84.

Shuwu M.P., B. Ranganna, K. B. Sureshaand R. Veena, 2011. Development of Value Added Lassi using Honey, The Mysore J. Agri. Sci., Vol. 45(4): ISSN-00478539.

Reshmi, S., K.M. Aravindhan and Suganya Devi, P. 2012. The effect of light, temperature, ph on stability of betacyanin pigments in Basella alba fruit, Asian J. Pharma. Clin. Res., Vol 5, Issue 4.

Vitti, M.C.D., Yamamoto, L.K., Sasaki, F.F., Aguila, J.S., Kluge, R.A. and Jacomimo, A.P. 2005. Quality of minimally processed beet roots stored in different temperatures. Brazillian Arch. Biol. Technol., 48: 503 - 510.

\section{How to cite this article:}

Shairee Ganguly, Chaitali Chakraborty and Kakali Bandyopadhyay. 2017. Development and Characterization of Biocolour (Beta vulgaris) Enriched Low Calorie Lassi (Yogurt Based Beverage). Int.J.Curr.Microbiol.App.Sci. 6(4): 2265-2270.

doi: https://doi.org/10.20546/ijcmas.2017.604.263 